\title{
Strategies for instructional computing
}

\author{
N. JOHN CASTELLAN, JR. \\ Indiana University, Bloomington, Indiana 47405
}

\begin{abstract}
Instructional computing in psychology has become increasingly important to undergraduate and graduate curricula. Four modes of instructional computing, drill and practice, data generators, experiment simulators, and gaming, are described and illustrated with actual programs. Implications of recent developments in cognitive psychology for instructional computing are outlined. Factors in the design of high-quality materials are described, and problems and opportunities for publication and distribution are discussed.
\end{abstract}

Although the original theme of the National Conference on the Use of On-Line Computers in Psychology began with a major emphasis on laboratory applications, there were, at the same time, developments in instructional computing and computer-assisted instruction (CAI) that were not emphasized at meetings during those early years. This implicit (and sometimes explicit) policy was appropriate, since many of the applications of computers to instruction were of the "traditional" drill-and-practice sort or skill-building programs popular at the time and the level of sophistication of such software was relatively low. Moreover, there often seemed to be a clear distinction between "laboratory" computing and "instructional" computing. Laboratory computing was the application of computers to the study of behavioral phenomena. The computers used by psychologists were often dedicated to a particular task (or paradigm), and often the only feasible instructional computing was training graduate students to use the computer system to conduct research. Sometimes faculty would take graduate (and even undergraduate) classes to their laboratories to observe the experimental procedures used or to participate in experiments, with the expectation that the experience would enhance the students' understanding of behavioral phenomena. However, there was seldom any attempt to integrate such laboratories into the curriculum. This may have been appropriate, in part because the laboratories were often externally funded research laboratories, and in part because the research conducted was often at the forefront of the field and it would be difficult and perhaps inappropriate to merge such specialized work into undergraduate curricula.

Three factors worked to bring a gradual end to the dichotomy of research and instructional computing. First, significant advances were made in the standardization of interfaces, which made it possible to quickly and inexpensively interface a variety of devices to computers. Second, the decreasing cost of minicomputers and the introduction of microcomputers made the development of computer-based instructional strategies feasible, practical, and, most important, transportable between laboratories and institutions.
Third, developments in cognitive psychology made the application of computers to instruction compelling as demonstrations of principles being studied in the laboratory.

Here, I will cover two aspects of instructional computing. One aspect I have termed "modes of instructional computing" and the other, "instructional design." Instructional design is the organization of material for use in learning situations. It concerns the way in which the material is displayed, the manner in which the materials flow, and the manner in which errors or mistakes are handled. In short, instructional design might be termed "human factors" in instructional computing. By "mode of instructional computing," I mean the strategy used by the instructor to teach the substantive concepts in the course.

\section{MODES OF INSTRUCTIONAL COMPUTING}

In instructional pedagogy, there are several ways to teach material. Most psychology faculty are familiar with these approaches, which include, among others, lectures, seminars, discussion groups, and Socratic dialogues. Most good teachers employ each of these methods when appropriate, sometimes using different methods within the same course. In a similar fashion, there are several different instructional computing strategies, four of which are particularly applicable to teaching psychology and other behavioral and social sciences. These are drill and practice, data generators, experiment simulators, and gaming. The discussion will describe each and provide examples.

\section{Drill and Practice}

The drill-and-practice mode of instructional computing is perhaps the oldest form available and, for some purposes, can be very useful. If there are basic skills to be learned, repetition with a large number of examples can be a fruitful way to learn, especially if the material to be mastered can be reduced to small chunks. Although many people have argued that it is important to understand material and that facts and details are unimportant, it is worth remarking that the burgeoning literature 
on problem solving is showing that expertise depends upon a foundation of a large number of facts.

A good example of the use of drill and practice in teaching psychology is assisting students to gain mastery of mathematical and statistical techniques. Students enrolling in undergraduate statistics courses need to master certain algebraic skills, such as factoring, reducing or simplifying algebraic and numeric fractions, solving simple equations, using summation, and so on. The Algebra Drill and Practice courseware (Detmer \& Smullen, 1981) is an example of this genre. It assumes that the student has been exposed to the general mathematical principles and theory and encourages him or her to improve skills. Suitable feedback is provided when errors are made so that subsequent problems may be solved correctly.

At the beginning of a session with this courseware, the student is asked to choose a topic (e.g., factoring or word problems). The student is then asked if he or she would like to see worked examples (see Figure 1). After the student has reviewed one or more examples, a series of test trials begins. A problem is displayed, and the student is asked to solve it. If the student's answer is correct, the next problem is given. After an error, the student may try again. However, after the second error, the student is given the correct answer and may choose to see the solution to the problem worked out in detail. Finally, after some number of problems, the student receives performance feedback.

Programs such as this have certain advantages over traditional methods of drill and practice. First, feedback is immediate, and depending upon whether the student is correct or has made an error, appropriate feedback is possible, and the student may work additional problems to test understanding. Second, unlike a textbook or workbook, the program can provide a large variety of problems. This prevents the student from increasingly relying upon rote memory in producing a particular solution. (Students may memorize techniques, but many view that as essential to subsequent understanding and application of theoretical ideas.)

\section{Data Generators}

A particularly popular sort of instructional computing technique involves the generation of artificial data for analysis by students. Examples include EXPER SIM (Main, 1972, 1974) and FIRM (the Florida interactive modeler; Levy, 1982). Typically, these progams consist of procedures for generating random data that conform to a general linear model with specified parameters. The designer determines for some known behavior (or complex of behaviors) the expected results based upon reports in the literature. That is, the main effects and interactions (whether significant or not) are specified so that when a student executes the program, the results will be similar to those obtained in the "real world."
Extant systems vary in their flexibility; some require the student to specify a cell of the design, others permit the student to test marginal cells, and some permit the introduction of "unanticipated" variables after the system is built and specified.

After examining the output from the chosen cell(s) in the design, the student is expected to analyze and interpret the data in order to gain understanding of the problem.

These systems usually require the instructor to provide some sort of background reading material before the student begins to generate results. Scoring systems are often used to discourage students from systematically testing all possible cells in order to discover relations among the independent and dependent variables. That is, the intent is to encourage students to generate thoughtful designs rather than blindly exhaust all alternatives.

An interesting sort of data generator is a program called "SAMP: Survey Sampling" (Gilbert, 1982). The purpose of the program is to illustrate the general notions of sampling variability and the various methods of sampling from populations. Such a courseware package would be appropriate in courses in statistics and survey sampling. As an illustration of a data generator package, and one that is well designed, I would like to run through an illustrative set of frames (see Figure 2).

Another data generation program that appears quite different from SAMP is one that deals with classical conditioning. It was developed by Benedict and Butts (1981) and provides some insights into program design. Although the program has many options, I would like to illustrate only one of them. One of the experiments from which data may be obtained is conditioned suppression. In it, the student should have read some prefatory material from a text or had a special lecture in class. The student is then ready to try his or her hand at some data sets. In these programs, the student has many options. We shall choose only one example to show the general idea (see Figure 3).

Note that the student must choose several options. Also, after the options are set, the program generates trial-by-trial data that the student may record to be plotted and analyzed later. Moreover, after listing the data, the program plots the data to illustrate better the form of the results. Additional data (i.e., replicates) for the same condition can be obtained, as well as data for the other conditions.

\section{Experiment Simulators}

Experiment simulators are those software systems that enable the student to actually "run" an experiment. Typically, it is expected that the student will be the subject in the experiment; however, many of the available programs enable the student to vary some parameters and run other "subjects" in the experiment. Summary data about performance are provided, and the student is expected to analyze them in order to fully 


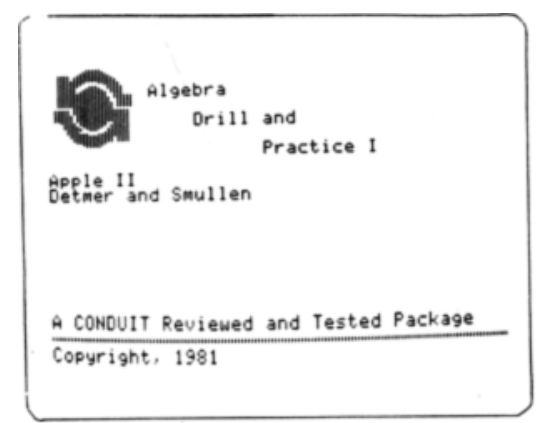

choose an fiew from the

1 Algebraic Fractions

2. N Nimeric Fractions 4
5
5
5
Snd

Type the number of your choice and press the RETURN key. Enter $(1,2,3,4,5$ or 6$)$ -
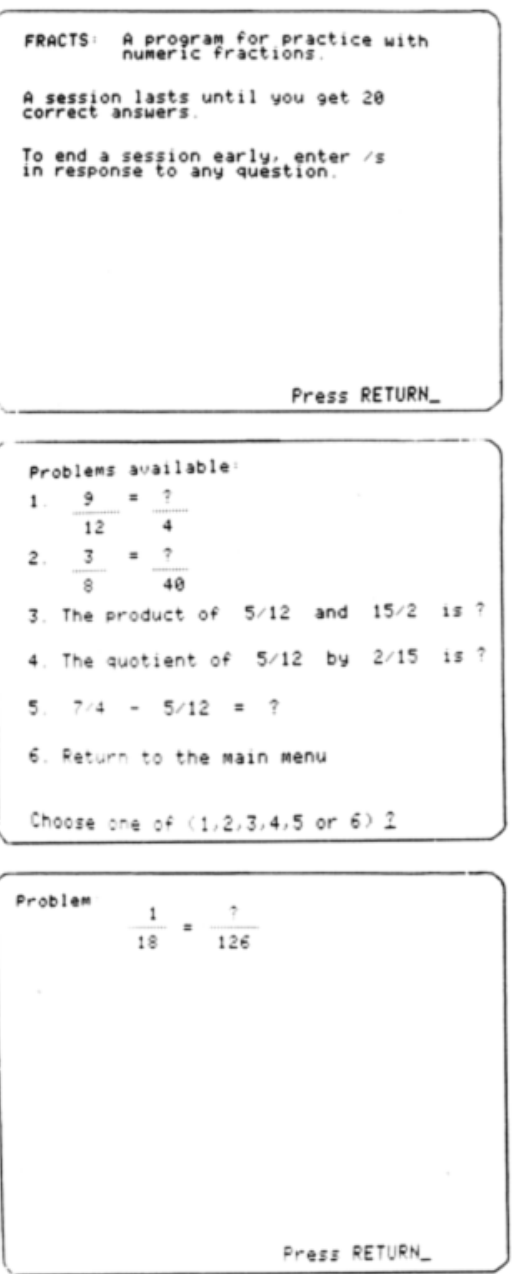

Problem

$$
\frac{1}{18}=\frac{?}{126}
$$

Solution

Since $126 / 18=$ ?

$$
\frac{1}{18}=\frac{(7) * 1}{(7) * 18}=\frac{7}{126}
$$

The answer is?

(The answer is always a whole number)

Would you like to see an example?

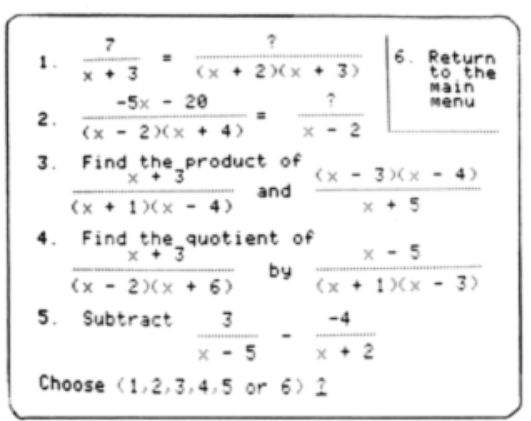

$$
\begin{aligned}
& \text { Problem: } \\
& \frac{3 x+6}{(x-1)(x+2)}=\frac{?}{x-1}
\end{aligned}
$$

For the solution Press RETURN_

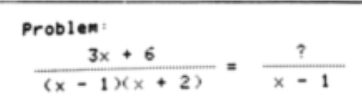

Solution:

$$
\begin{aligned}
& \frac{3 x+6}{(x-1)(x+2)} \\
& \begin{aligned}
\text { Solution: } & \frac{3(x+2)}{(x-1)(x+2)} \\
& =\frac{3}{x-1}
\end{aligned}
\end{aligned}
$$

The answer is 3

Would you like to see an example?

Ok, here's a problen.

$$
\frac{7 x-21}{(x-2)(x-3)}=\frac{2}{x-2}
$$

Figure 1. Illustrative frames from Algebra Drill and Practice (Detmet \& Smullen, 1979) showing initial menu options, worked example, and typical problem. 

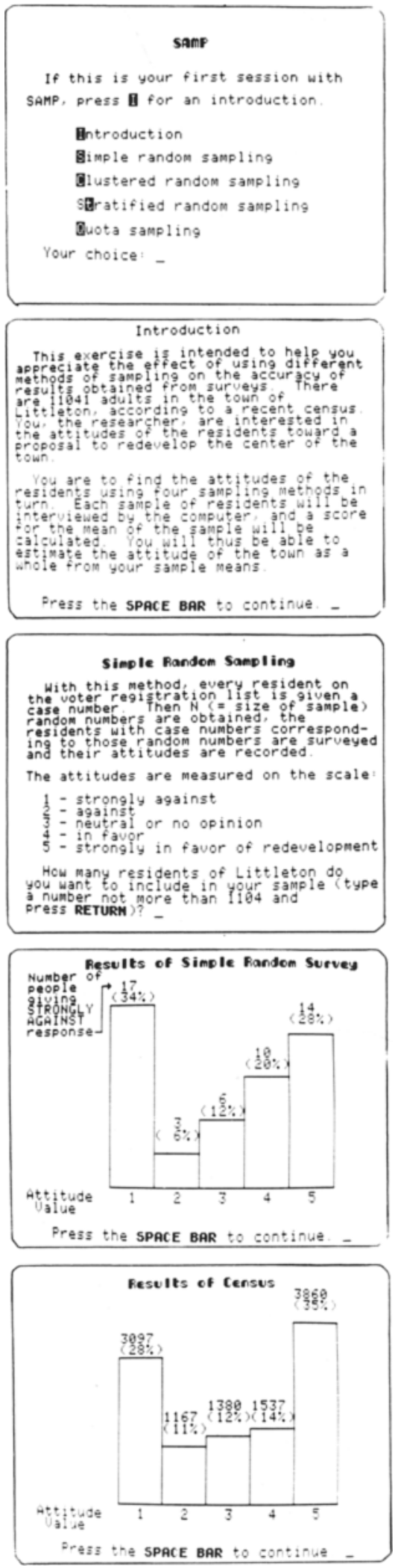

Figure 2. Illustrative frames from $S A M P$ : A ComputerAided Learning Package for Teaching Survey Sampling (Gilbert, 1981) that show screen design and student options. understand the phenomenon being studied. One of the first instructional packages to do this was "Cognitive Psychology" (Bewley, 1979).

It should be noted that these programs are often noisy examples of actual experimental procedures. That is, they often involve the use of standard keyboards for input and standard video monitors for output. Such equipment usually provides precision adequate to illustrate basic phenomena; however, the degree of control is seldom adequate to provide publishable results. But the intent is not to provide a flexible research instrument; rather, the goal is to run "standard" experiments for the instructional laboratory that may be used by students with minimal computing experience.

The example I would like to pursue is one that exam. ines problem solving behavior. While there are many interesting programs, the one 1 have chosen illustrates the "General Problem Solver" (Bewley, 1979). In it, the student not only serves as a subject but may conduct a simulation that mimics the General Problem Solver. Although dated, this program illustrates two aspects of experimental simulations (see Figure 4).

There are many other sorts of experiments that can be found in packages, such as the Laboratory in Cognition and Perception developed at the University of Florida (Fischler, Griggs, Warner, Sherman, \& Levy, 1979) and Keenan's Laboratory in Memory and Cognition (Keenan \& Keller, 1980, 1983). These deal with materials ranging from psychophysics to learning to cognitive processes in perception, language, and thought.

\section{Gaming}

In some disciplines, gaming simulations are widely used. Gaming simulations involve the use of an abstract program or "game" to teach basic principles. One area in which gaming can be fruitful is teaching scientific inference. For example, in the game "Tribbles" (Von Blum \& Hursh, 1976), the student must generate hypotheses about rules governing the behavior of mythical creatures on a distant planet. The program is designed so that the student may test various behavioral hypotheses in a proactive way, and it is very difficult to solve the inference problem by passively observing behavior. For some skills, gaming programs can be very useful. Because the task is abstract, the student is not burdened by prior experience that might either be misleading or prevent appropriate inferences' being made.

Tribbles is designed for use in an introductory course in methodology. It was first used in biology courses, but the range of application is wide and embraces psychology. The intent is to give students a taste of hypothesis testing and the need for control and design.

\section{DESIGN OF INSTRUCTIONAL PROGRAMS}

A great deal is known about instructional design and the way to present material so that it is as easy and enjoyable to learn as possible. However, as psychology editor for CONDUIT. I repeatedly have been surprised 

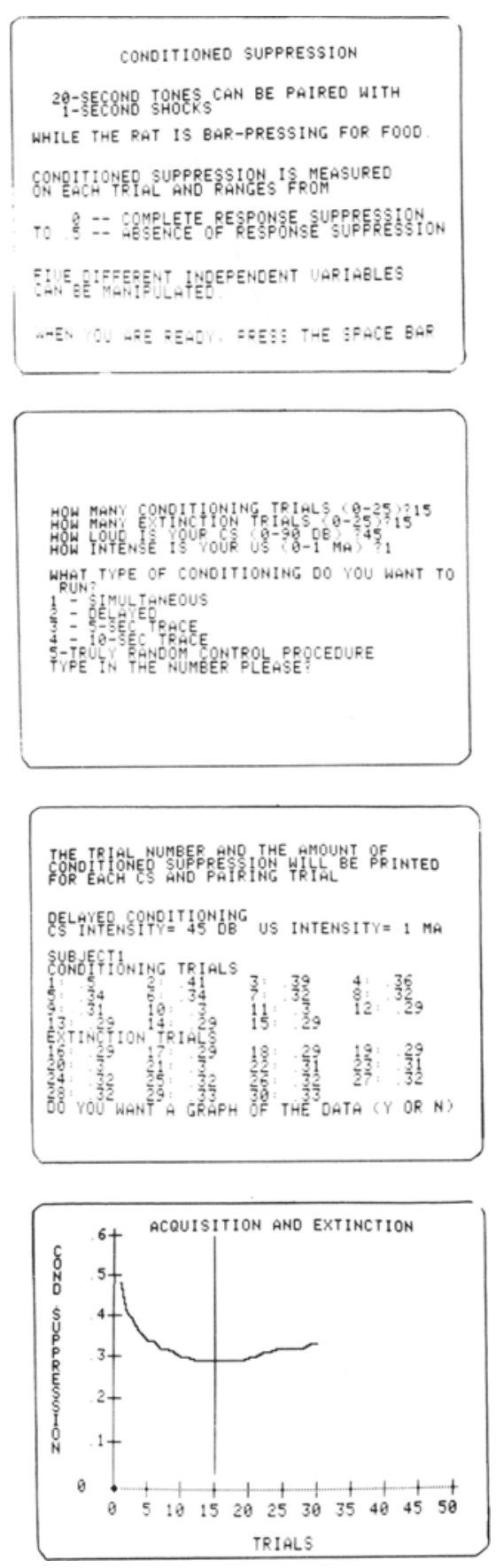

Figure 3. Illustrative frames for CLASSCONSIM (Benedict, 1982) showing student options, data summary, and data plot.

to see computer-based instructional packages designed by psychologists that show very little knowledge of the principles of design that could make a mediocre package excellent. A decade ago, psychologists were delighted to have any sort of simulation or computer-based instructional materials. Today, we have students who demand, quite properly, high-quality materials. We must be able to deliver computer-based instructional material of the highest quality if we wish to stimulate and challenge students.

When I discussed this matter with a colleague recently, she pointed out that if a psychologist wanted to do research on some phenomenon, he or she would read the relevant literature on both the phenomenon and the methodology to be employed. Few psychologists (or other academicians, for that matter) employ the same strategy in the development of instructional materials. However, like the researcher who does background and preliminary research on a scientific problem, the psychologist who does the relevant background research and methodology review in instruction stands a better chance of developing superior computer-based instructional materials.

Over the past decade, we have learned much about instructional design. One way to see the change is to compare textbooks. The interested reader should compare the best selling introductory psychology text by Atkinson, Atkinson, and Hilgard (1983), now in its eighth edition, with the first edition (Hilgard, 1953). Among other things, there are changes in the use of figures and photographs, type styles, insets, and ragged margins. Not only has the content changed to reflect contemporary developments and thinking in psychology, the style of presentation has changed as well. One might argue that regardless how current the substantive content is, the book would have been long out of print had the design not evolved over the years.

While it is not my purpose to present a definitive compendium of design techniques, I would like to outline some aspects that may serve as a useful starting point for further examination by potential curriculum developers. In order to provide a context for the points to be raised, I would like to begin with a set of principles that should guide the development of materials: (1) Students will be using the computer for instructional purposes for a long time. Individual sessions may last $1 \mathrm{~h}$ or longer, and repeated sessions are often necessary. (2) The object of the instructional material is not to teach computing. The purpose of using the computer is its efficiency or special capacity. (3) Learning experiences should be interesting and varied. Boredom and tediousness seldom facilitate learning. (4) Successful packages will treat the keyboard not as a typewriter keyboard or computer terminal, but as a response/ control panel. Similarly, the display should be considered an information transmission panel. (5) The developer should have clear instructional goals for the materials that are being developed.

In the remainder of this paper, I shall give some ideas and examples that illustrate some of the ingredients of a good package.

\section{Display Design}

Perhaps the guiding principle in display design is that 

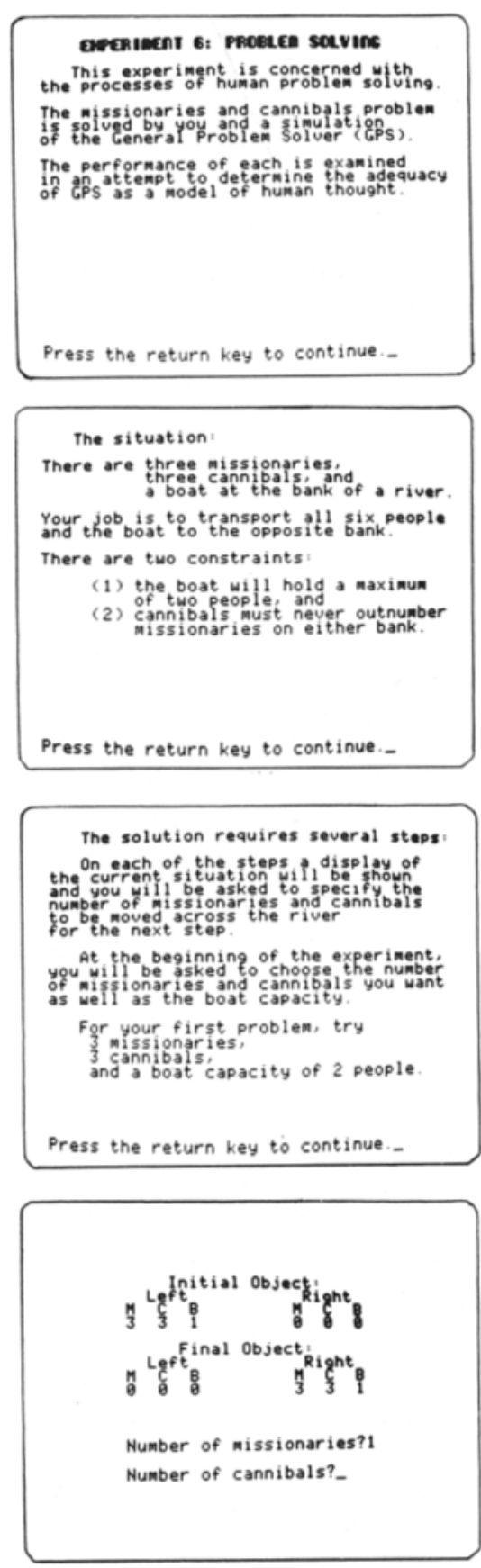
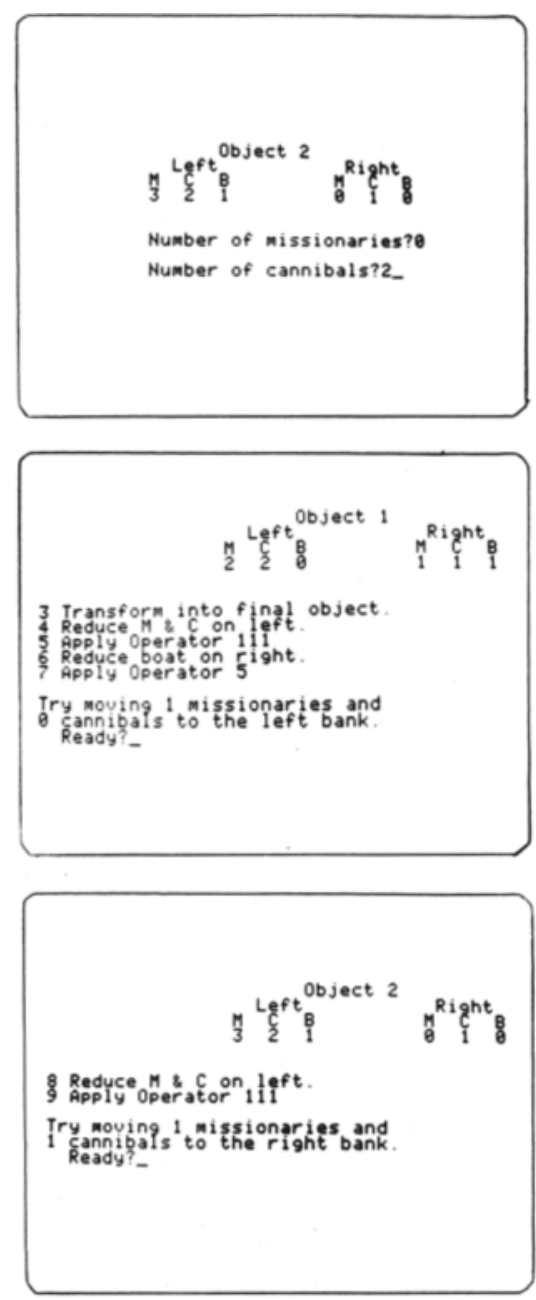

Figure 4. Illustrative frames from Cognitive Psychology: A Computer-Oriented Laboratory Manual (Bewley, 1979) that consist of successive screens seen by student. Framework for display follows notational schemes used in the General Problem Solver.

the display should be clear and easy to read. There are several ways to achieve good displays that will enable students to learn better and faster.

(1) Use open space. The contemporary American composer John Cage (Cage, 1961) has argued that in music, the space between notes is more important than the notes themselves. Instructional designers need to recognize that space can be used to make displays clearer and more efficient. Too many of us are accus- tomed to writing instructions that may be typewritten on as little paper as possible. Economy of words is important, but it does not follow that saving space is an economy that can be justified in the design of learning environments.

(2) Messages should be clear. Ambiguous language and jargon should be avoided. In addition, clarity is enhanced if text is broken up by phrases and sentences. Unlike a typed manuscript, there should be no hyphen- 

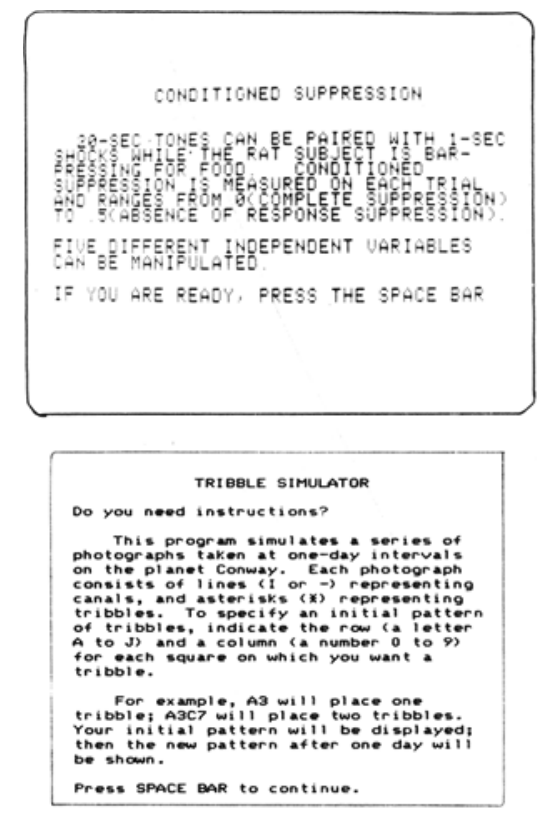

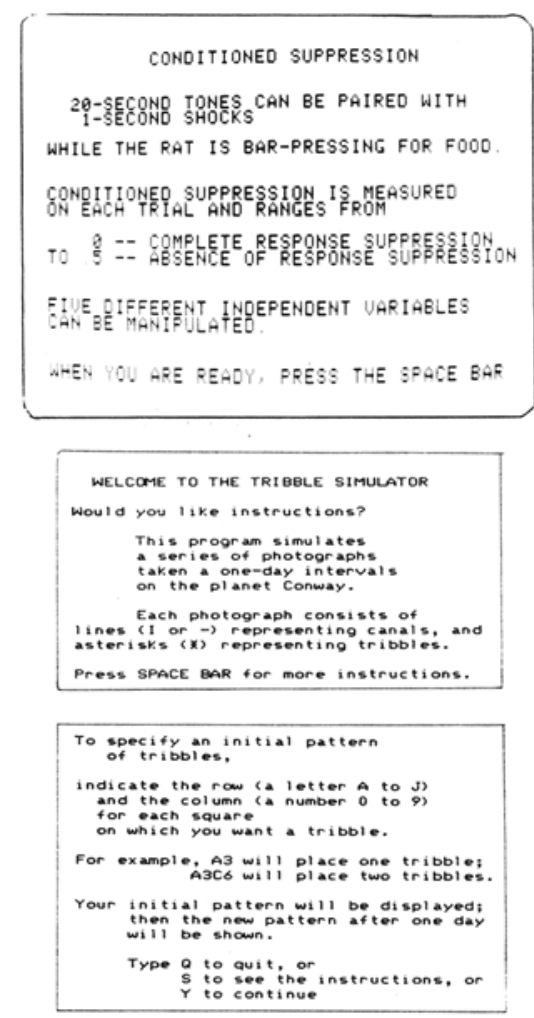

Figure 5. Frames showing differences in screen design. The left half of the figure shows original screen design; the right half shows screen layout revised for greater clarity.

ation, no splitting of phrases between lines, and no beginning of sentences in the middle of a line. While it is obvious that it may not be possible to construct displays that satisfy these requirements, the goal should be ever present. Supppose that you have a 42-character sentence to display on a monitor that can handle only 40 characters/line. An effort should be made to rewrite the sentence to make it fit on a single line. Frequently, a synonym will solve the problem. In longer passages, it might be possible to rearrange the text so that is more legibly displayed.

There are two examples that will illustrate these principles. The original text is taken directly from instructional materials that have been used in the format described. The left half of Figure 5 shows the original format of the text; the right half of the figure shows a revised format. While other formats could be used, the revised format should be easier to read and clearer to the student.

(3) Use all margins. Every display has a top, bottom, right, left, middle, and so on. To provide interesting and clear material, all aspects should be used. While we are accustomed to reading text aligned on the left margin, centered text and right-justified text can be quite effective. Figure 6 illustrates the sorts of things that can be done.

(4) Mix type sizes and fonts. On many computers, it is possible to use different type fonts. The Apple DOS TOOLKIT contains routines and coding to enable a programmer to use many different styles of characters. For some purposes, headings, warnings, special information, and so on, different character fonts can be effective. Some newer systems also include the capability of using different-sized characters. While such flexibility is not currently possible on all microcomputers or terminals, most have reverse video and field blinking features that can be used to good effect. (1 recently discovered that on my microcomputer, I can underline and "overline" the displayed text.)

(5) Color should be used. Until recently, many people argued that color was an unnecessary luxury in instructional computing. This belief was reinforced by the relatively poor quality of color displays. However, there are two developments that make color more valuable in instruction. First, the rapid development of the video game industry has produced a generation of students who "demand" color. Second, the introduction of intermediate-priced RGB color monitors has placed high-quality color displays within the reach of most budgets. However, there is an important caution regarding the use of color. Most psychologists know that different colors and hues can have different meanings. Therefore, when displaying a bar graph, for example, the choice of colors should be carefully made. While careful choice of color may enhance learning, haphazard choice can have unintended effects upon the material to be learned. Moreover, instructional designers must realize that a significant number of students are 


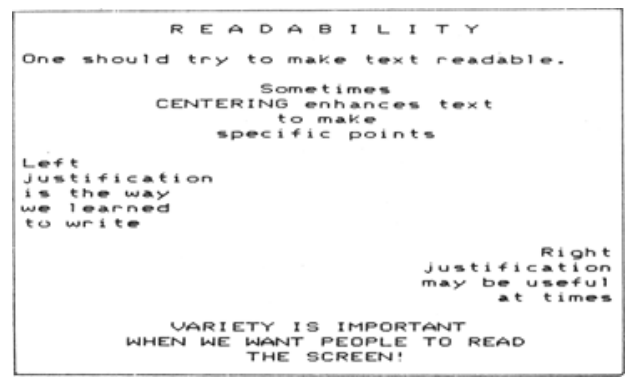

Figure 6. Facsimile screen showing justification options.

color-blind, and colors must be chosen to enable effective discrimination of displays for such people.

While I have listed several aspects of screen design that should be considered in computer-based instructional development, there is a dictum that should always be observed: Be judicious and strive for clarity, not cleverness. The clever display has one drawback; it draws attention away from the principles to be taught. Also, one person's wit and humor may be judged offensive by others who do not have the same taste.

\section{Input Design}

Like display design, the manner in which input is managed is critical to the success of a good instructional program. One of the first things that should be done in developing an instructional program is to determine what inputs or student responses are necessary. Once the inputs are defined and it is known what values and what range are necessary, the program can be designed to make optimal use of input. There are several principles concerning input that may be used to guide the development of materials.

(1) The number of keystrokes should be minimized. When making a response, the effort should be as small as possible in order to keep attention directed to the learning task. This leads to a corollary:

(2) The use of RETURN or ENTER should be minimized. For many purposes, the RETURN key is superfluous. If an application requires a single keystroke, there is no need for additional keystrokes. The languages used in most applications, BASIC, FORTRAN, and PASCAL support single-key input without the need for the use of RETURN or ENTER. In many applications, it should be necessary only to touch any key on the board. However, it is poor design to say "type any key," since this can lead to difficulty in later applications when a more structured response is required. It would be far better to say "touch the SPACE BAR to continue." (Incidentally, the colloquial phrase "hit the RETURN key," or "hit" anything, should be avoided. While this is a subtle matter, one should avoid ambiguity in specifying responses.)

(3) All input should be string input. While testing strings for " $\mathrm{Y}$ " and " $\mathrm{N}$ " is common, it should be noted that input of numeric data is fraught with difficulty. If the data are input as strings, the program has control over the error recovery and meaningful diagnostics may be provided. Efficient functions exist for converting strings into numeric equivalents. Some languages give the user control of diagnostics (e.g., the ONERROR statement in some BASIC interpreters), which minimizes the need for program designers to write their own code.

(4) Consider control commands carefully. Some programmers become enamored of their coding prowess and use sophisticated branching commands in their programs. For example, a command like "jump to page" may be very handy in word processing and text processing systems; however, such commands in instructional modules will be seldom used, and their use, however infrequent, may be poor pedagogy. As a teacher, would you want the student to leap through the material? An important and necessary feature is the capability to go to the next page and to go back one page at a time. Unless there is a special and justifiable need, greater flexibility should not be provided. Finally, from a human-factors view, one must distinguish user-controlled jumps from program-controlled jumps intended by the system designer.

(5) Input should be simple and consistent. One of the most frequent problems encountered in courseware is inconsistency in the control and typed information entered by students. The procedures used should be consistent so that once the basic principles of operation of the module are mastered, they may be easily and directly applied in new contexts. Throughout a program, commands should be utterly consistent. Moreover, the commands should have some meaning. While choice alternatives may be labeled 1,2,3, and so on, it is far better to use partial mnemonics, such as "a" for add, "s" for subtract, and " $d$ " for delete. With a little forethought, fast, clear, and accurate input procedures may be incorporated into instructional programs.

\section{Error Handling}

The ability to process errors in input is one of the very attractive features of instructional computing. There are two kinds of errors: One has to do with the manner in which responses are made and data are entered into the computer (e.g., typing the wrong key). The other has to do with substantive errors a student may make when typing input (e.g., typing " 5 " as the answer to " $2+2=$ ?"). Both errors should be avoided. The former error is due to poor program and system design. The latter is due to poor instructional design. Ideally, the student should not make errors. However, the ideal is seldom achieved. Therefore, since we cannot eliminate errors, we should make their correction as benign as possible. The following principles concerning error handling should eliminate or at least minimize the frustration students feel when using computer-based instructional materials.

(1) Error hańdling should be in context. There is nothing more frustrating than to see the message "ERROR NUMBER 125" or "INPUT ERROR AT 
LINE 610". For most students, such errors are utterly meaningless. Therefore, errors should be in context (e.g., when an alphabetic character is typed in place of a number, a suitable comment would be "The answer should be a number"). However, simply displaying such a comment may not help the student very much.

(2) Error comments should be clear. After informing the student that an error has occurred, the comment should make clear what is to be done in order to correct the error. Thus, the comment illustrated above could be modified to something like "The answer should be a number, please try again." Such a comment not only tells the nature of the error, but tells what action should be taken next. Of course, exactly what should be done depends upon what the error was and what the instructional design expects. Some instructional designs do not tell the student that an error has occurred; rather, the program branches to an appropriate lesson that enables the student to learn the appropriate or correct responses.

(3) Corrections should be easy to make. Consider the case of an incorrect number entered by a student working at a terminal. The program should erase the incorrect response and position the cursor at the proper location on the screen before waiting for a new response. The student should not be expected to do fancy or complicated cursor movements, backspaces, and so on. Typeover of an error should be done only when the pedagogy dictates such a procedure.

(4) Help should be available. It is relatively easy to design "help screens" that a student can invoke if he or she is unable to determine precisely what sort of response should be made. While help can be overdone, it is rarely the case that students report that a program is so clear that they had no questions about how to proceed.

(5) Error counters should be used. In spite of the best efforts at good design, students may persist in making errors. Although it is important to have good techniques for correcting errors, additional steps should be taken if the errors exceed some criterion. Error counters should be used, and if the number of errors made by the student exceeds the criterion, the program should halt, a special message should be printed, and the program should branch to a routine that takes corrective action. There is nothing more frustrating to a student than making errors and not being able to go ahead, back up, or go sideways. A student who must walk away from a terminal with errors displayed on it advertises to the entire world not only that an error was made, but that the student got stuck somewhere deep within the program and failed to master the system.

\section{Documentation}

The last topic to be covered here is the problem of documentation. There are two types of documentation. One type is technical and is of use to people trying to get programs to execute properly or modify them for special purposes. The other type of documentation is that which is in the form of an instructor's guide or student's guide.

Documentation is consistently a weak link. The reasons for this are complex. First, people developing instructional materials often do so for their own courses before they distribute them to others. When developing something for one's own class, one knows exactly how the materials fit into the course. In explaining the materials to others, one must describe not only the software, but the manner in which it may be integrated into the course. There is often little motivation or interest in doing this, since when using the materials in one's own course, such documentation is not needed.

A second reason for poor documentation is that it is anticlimactic. When the time comes to write documentation, the instructional developer is anxious to move on to other things.

Whatever the cause, the result is that documentation is often hurried, unclear, and poorly written. (Most reviewers of manuscripts for scientific journals could testify that people writing instructional programs have no monoply on poor writing.)

As with scientific writing, the best workbooks and guides are those that have been read and critiqued while in draft form by someone knowledgeable about the application. It is important to share materials with others in order to get the feedback necessary to write good documentation.

\section{SOME SELECTED REFERENCES}

There are many references relevant to the development of high-quality instructional materials. Many good papers may be found in the annual proceedings of this conference and the other issues of Behavior Research Methods \& Instrumentation. One source of information is CONDUIT ${ }^{1}$ which has published useful books for faculty and others interested in instructional development, for example, the Author's Guide (Peters \& Johnson, 1978), which describes many aspects of the creation of courseware, including design, development, style, packaging, and review. This guide is currently being revised to reflect recent developments in microcomputing. A second publication from CONDUIT is The User Frontend (Hirst. 1979), which describes a generalized input facility for conversational programming. The publication consists of a manual and set of routines that provides a unified processing mechanism for student input. These include string handling and conversion routines for numeric input, "help" routines, and a variety of editing functions. Use of these routines, or ones like them, can eliminate system error problems resulting from student input and provide efficient and coherent computer-student interaction.

A recent book that contains a broad overview of instructional computing and the design of computing dialogues is Learning with Computers (Bork, 1981). This book also contains an extensive bibliography. 
Several professional associations publish useful journals and newsletters. While some are geared to the elementary and secondary school market, others emphasize higher education. The Association for Computing Machinery (ACM) has two relevant special interest groups. ${ }^{2}$ SIGCHI (Special Interest Group in Computer and Human Interaction) draws its primary membership from the social and behavioral sciences. ${ }^{3}$ Of particular interest is a special publication of the proceedings of a conference on Human Interaction and the User Interface (Borman, 1982). Another ACM special interest group is SIGCUE (Special Interest Group on Computer Uses in Education), which publishes a quarterly bulletin. The bulletin is a useful way to keep up on new techniques and developments in instructional computing.

Another organization with a fine journal is the Association for the Development of Computer-Based Instructional Systems (ADCIS), which also hosts an annual meeting. ${ }^{4}$

There are dozens of computer-based education conferences and seminars. Perhaps the best is the National Educational Computing Conference (NECC) held each summer. This meeting is jointly sponsored by 13 computing and education associations. The annual proceedings of the conference contain many useful papers. ${ }^{5}$

Finally, I should conclude with the observation that perhaps the best way to learn about developing instructional materials is to look at as many different packages as possible. While the quality does vary, I believe that you will be surprised by the very high quality of some of the packages available.

\section{REFERENCES}

Atkinson, R. L., Atkinson, R. C., \& Hilgard, E. R. Introduction to psychology. New York: Harcourt Brace Jovanovich, 1983.

Benedict, J. O., \& Butrs, B. D. Computer simulation or real experimentation: Is one better for teaching experimental design? Teaching of Psychology, 1981, 8, 35-38.

BEWLEY, W. L. Cognitive psychology: A computer-oriented laboratory manual. Wentworth, N.H: COMPress, 1979.

Bork, A. Learning with computers. Bedford, Mass: Digital Press, 1981.

Borman, L. (Ed.). Proceedings Part II: Human interaction and the user interface. New York: Association for Computing Machinery, 1982.

CAGE, J. Silence. Middlebury, Conn: Wesleyan University Press, 1961.

Detmer, R. C., \& Smullen, C. W., III. Algebra drill and practice. Iowa City, lowa: CONDUIT, 1981.

Fischler, I. S., Griggs, R. A., Warner, S. A., Sherman, M. E., \& Levy, C. M. Laboratory in cognition and perception. Iowa City, Iowa: CONDUIT, 1979.

GILBERT, G. N. SAMP: A computer-aided learning package for teaching survey sampling. lowa City, lowa: CONDUIT, 1982.

HilgaRd, E. R. Introduction to psychology. New York: Harcourt Brace Jovanovich, 1953.

Hinst, S. The user frontend. Iowa City, Iowa: CONDUIT, 1979.

Keenan, J, M., \& Keller, R. A. Teaching cognitive processes: Software for laboratory instruction in memory and cognition. Behavior Research Methods \& Instrumentation, 1980, 12, 103-110.

Keenan, J. M., \& Keller, R. A. Computer laboratory in memory and cognition. Iowa City, Iowa: CONDUIT, 1983.

LEvy, C. M. FIRM: The Florida interactive modeler. Iowa City, Iowa: CONDUIT, 1982.

MaIn, D. B. Toward a future-oriented curriculum. American Psychologist, 1972, 27, 245-248.

MAIN, D. B. EXPER SIM: Experimental simulation. Creative Computing, 1974, 3, 18-21.

Peters, H. J., \& Johnson, J. W. Author's guide. Iowa City, Iowa: CONDUIT, 1978.

Von Blum, R., \& Hursh, T. M. Tribbles: An introduction to the scientific method. Iowa City, Iowa: CONDUIT, 1976.

\section{NOTES}

1. CONDUIT is a nonprofit organization that reviews, tests, packages, and distributes educational computer software, with major emphasis on materials suitable at the collegiate level. Begun in 1971 with support from the National Science Foundation (NSF), CONDUIT is currently affiliated with the University of Iowa and funded in part by NSF and the Fund for the Improvement of Postsecondary Education (FIPSE). For further information, write to CONDUIT, P.O. Box 388, Iowa City, Iowa 52244.

2. Information concerning membership in and publications of the ACM or its special interest groups may be obtained from the Association for Computing Machinery, Inc., P.O. Box 12115, Church Street Station, New York, New York 10249.

3. Before mid-1982, SIGCHI was known as SIGSOC, Special Interest Group on Social and Behavioral Science Computing.

4. Information concerning ADCIS may be obtained from ADCIS International Headquarters, Miller Hall 409, Western Washington University, Bellingham, Washington 98225 .

5. Information concerning proceedings of the NECC conferences may be obtained from Ted J. Sjoerdsma, Computer Science Department, University of Iowa, lowa City, Iowa 52242. 